NASA Technical Memorandum 85728

USAAVSCOM TECHNICAL REPORT 83-B-6

NASA-TM-85728

19840007131

ANALYSIS OF LOCAL DELAMINATIONS AND

THEIR INFLUENCE ON COMPOSITE LAMINATE BEHAVIOR

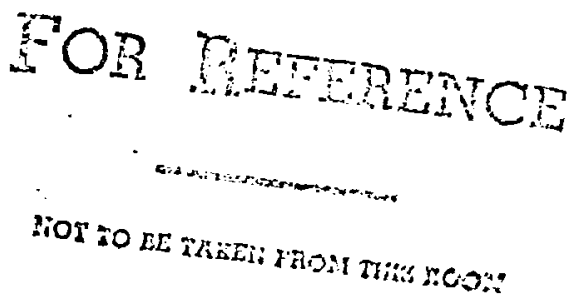

T. Kevin O'Brien

JANUARY 1984

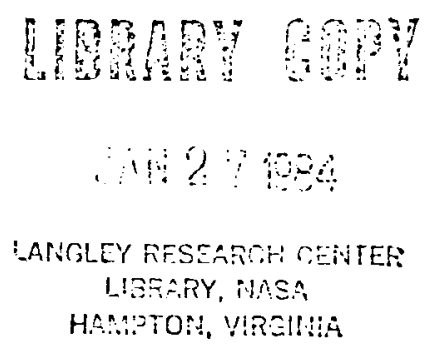

N/Sก

National Aeronautics and Space Administration 


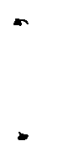




\title{
ANALYSIS OF LOCAL DELAMINATIONS AND THEIR INFLUENCE ON COMPOSITE LAMINATE BEHAVIOR
}

\author{
T. Kevin O'Brien \\ Structures Laboratory \\ USAAVSCOM Research and Technology Laboratories \\ NASA Langley Research Center \\ Hampton, Virginia 23665
}

\section{SUMMARY}

An equation was derived for the strain energy release rate, G, associated with local delamination growth from a matrix ply crack. The critical $G_{c}$ for edge delamination onset in $\left[ \pm 25 / 90_{2}\right]_{S}$ graphite epoxy laminates was measured and used in this equation to predict local delamination onset strains in $\left[ \pm 25 / 90_{n}\right]_{s}, n=4,6,8$ laminates. A simple technique for predicting strain concentrations in the primary load bearing plies near local delaminations was developed. These strain concentrations were responsible for reduced laminate nominal failure strains in laminates containing local delaminations. The influence of edge delamination and matrix crack tip delamination on laminate stiffness and strength was compared. 


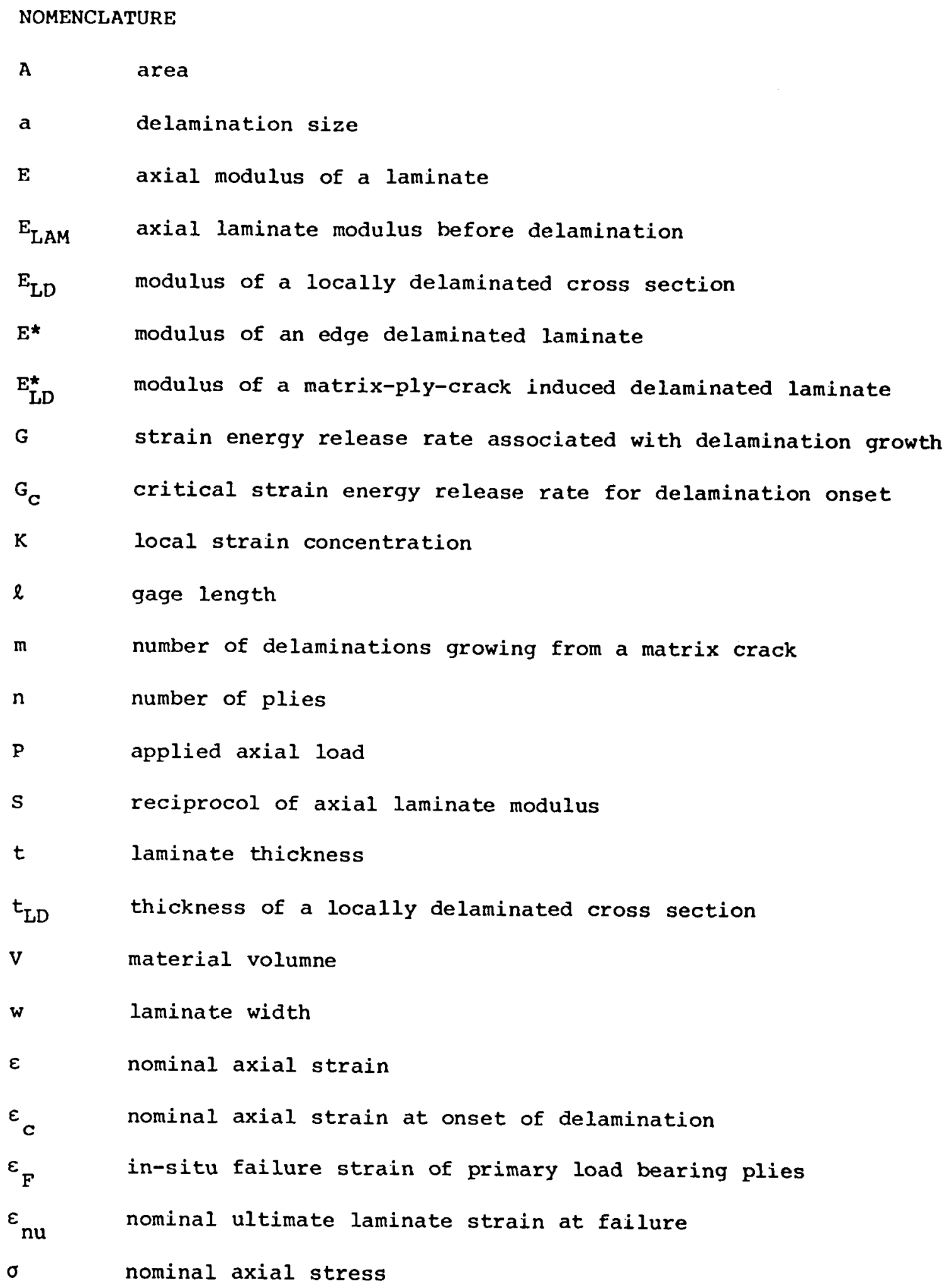




\section{INTRODUCTION}

One commonly observed failure mode in laminated composite materials is delamination between the composite layers. Delaminations may form and grow under both static and cyclic tensile loading. The most common source of delamination is the laminate edge, where high interlaminar stresses are developed due to the mismatch in Poisson contraction of the individual plies. These edge delaminations typically occur between $90^{\circ}$ plies and adjacent angle plies, with delaminations forming initially in a thumbnail shape, and rapidly becoming a delaminated strip that grows across the specimen width [1, 2]. The strain energy release rate, G, associated with this edge delamination growth, and the contributions of interlaminar tension and shear to $G$, have been determined previously for a variety of layups [1-4]. The influence of edge delamination on tensile stiffness and strength has been determined for a variety of layups as well $[1,5]$.

Another source of delamination is matrix ply cracks running parallel to the fibers in a ply. The interlaminar stresses that develop in the ply interface at matrix crack tips may cause local delaminations to form and grow [3, $6,7]$. The purpose of this investigation was to determine delamination onset strains for these local delaminations, and to determine their influence on tensile stiffness and strength. To this end, a strain energy release rate analysis of local delaminations was developed. Then, a simple technique for calculating strain concentration factors in the primary load bearing plies near localized delamination was developed. Finally, the influence of edge delamination and matrix crack tip delamination on laminate stiffness and strength were compared. 


\section{STRAIN ENERGY RELEASE RATE}

\section{Analysis}

For an elastic body containing a crack that grows under a constant applied load, $P$, the strain energy release rate, $G$, is given by [8]

$$
G=\frac{\mathrm{p}^{2}}{2} \frac{\mathrm{dC}}{\mathrm{dA}}
$$

where $C$ is the compliance, i.e., $C=\delta / P$, and $A$ is the crack surface area created. A similar expression may be written for $G$ in terms of the remote stress, $\sigma$, and the reciprocal of modulus, $s$, where $s=\varepsilon / \sigma$, by substituting

$$
C=\frac{s l}{w t}
$$

into equation (1). This yields

$$
G=\frac{1}{2} V \sigma^{2} \frac{d S}{d A}
$$

where $d S / d A$ is the rate of change in $S$ as the flaw extends, and $V$ is the volume of the body, i.e., $v=$ wtl.

In this study, the elastic body is a composite laminate containing a matrix ply crack through the thickness of $n$ off-axis plies, with delaminations forming at the matrix crack tip and growing in the ply interfaces (Fig. 1). For simplicity, the strain energy release rate associated with the growth of delaminations from a single matrix crack will be considered. In order to evaluate $\mathrm{dS} / \mathrm{dA}$ in equation (3), and hence $\mathrm{G}$, an equation for laminate compliance as a function of delamination size was developed.

Figure 2 illustrates a composite laminate containing delaminations growing from a matrix ply crack. The composite gage length, $\ell$, is divided into a locally delaminated region, $a$, and a laminated region, $\ell-a$. Assuming the composite displacements are the sum of the displacements in these 
two regions, and the total load, $\mathrm{P}$, is equal to the loads carried by the two regions individually, then using Hooke's law, $\Delta \ell=\mathrm{Pl} / \mathrm{AE}$, yields

$$
S=\frac{1}{E}=\frac{{ }_{L A M}}{\ell}\left[\frac{(\ell-a)}{A_{L A M}{ }_{L A M}}+\frac{a}{A_{L D} E_{L D}}\right]
$$

where $A_{L A M}$ and $E_{L A M}$ are the cross sectional area and modulus of the laminated region, and $A_{L D}$ and $E_{L D}$ are the cross sectional area and modulus of the locally delaminated region. Each of the areas in equation (4) represent only the cross sectional area that carries the applied load, hence,

$$
\begin{aligned}
& A_{I A M}=w t \\
& A_{L D}=w t_{L D}
\end{aligned}
$$

where $w$ and $t$ are the laminate width and thickness, respectively, and $t_{L D}$ is the thickness of the locally delaminated region that carries load, i.e., the thickness of the uncracked plies. Substituting equations (5) and (6) into equation (4) yields

$$
s=a\left(\frac{t}{l}\right)\left(\frac{1}{t_{L D} E_{L D}}-\frac{1}{t E_{L A M}}\right)+\frac{1}{E_{L A M}}
$$

Hence, the laminate compliance is a linear function of delamination size, a. Returning to Figure 2, the strain energy release rate associated with the growth of delaminations from a matrix ply crack can be calculated by assuming

$$
\begin{aligned}
& V=t w l \\
& A=m w a \\
& d A=m w d a
\end{aligned}
$$

where $m$ is the number of delaminations growing from the matrix ply crack. For the case illustrated in Figure 2, $m=2$, but for a delamination growing from a cracked surface ply, $m=1$. Substituting equations (8) into equation (3) and differentiating equation (7) yields 


$$
G=\frac{\sigma^{2} t^{2}}{2 m}\left(\frac{1}{t_{I D} E_{L D}}-\frac{1}{t_{L A M}}\right)
$$

or similarly, in terms of the applied load $P$,

$$
G=\frac{P^{2}}{2 m w^{2}}\left(\frac{1}{t_{L D} E_{L D}}-\frac{1}{t E_{L A M}}\right)
$$

Hence, as indicated in equations (9) and (10), the strain energy release rate is independent of delamination size. The magnitude of $G$ depends only on the laminate layup and thickness, the location of the cracked ply and subsequent delaminations (which determines $E_{L D}, t_{L D^{\prime}}$ and $m$ ), the applied load, $P$, and the laminate width, w.

\section{Experiments}

Previously, Crossman, Wang, and Law [2] performed tests on T300/934 $\left[ \pm 25 / 90_{n}\right]_{s}$ laminates, where $n$ varied from $1 / 2$ to 8 . They recorded the load at the onset of transverse cracking in $90^{\circ}$ plies, at the onset of delamination, and at failure. They used dye penetrant enhanced x-radiography to confirm the onset and extent of damage. Their results are illustrated in Figure 3, which shows the tensile strain at the onset of transverse cracking in the $90^{\circ}$ plies, at the onset of delamination, and at final failure, as a function of the number of $90^{\circ}$ plies, $n$, in the $\left[ \pm 25 / 90_{n}\right]_{s}$ laminates. A significant reduction occurs in both the delamination onset strain and failure strains for the $n>4$ laminates. Figure 4 shows a schematic of fracture sequences across the laminate width and at the edge (a) just before the onset of delamination, (b) just after the onset of delamination, and (c) just before final failure. The sequence illustrated in column (b), as $n$ increases from $1 / 2$ to 8 , indicates a transition between $n=3$ and 4 from thumbnail-shaped edge delaminations to local delaminations growing from a $90^{\circ}$ matrix ply crack. Hence, these data are useful for checking the strain energy release rate analysis for local delaminations. 
Delamination Onset Prediction

First, a critical value of $G_{C}$ was calculated from a previously derived equation for edge delamination [1],

$$
G=\frac{\varepsilon^{2} t}{2}\left(F_{L A M}-E^{\star}\right)
$$

using the measured delamination onset strain for the $\left[ \pm 25 / 90_{2}\right]_{s}$ laminate. The totally delaminated modulus, $E^{*}$, was calculated using laminated plate theory and the rule of mixtures [1]

$$
E^{*}=\frac{\sum_{i=1}^{q} E_{i} t_{i}}{t}
$$

where $E^{\star}=$ modulus of the delaminated laminate

$$
\begin{aligned}
& q=\text { number of sublaminates formed by the delamination } \\
& E_{i}=\text { modulus of the } i \text { th sublaminate formed by delamination, and } \\
& t_{i}=\text { thickness of the } i \text { th sublaminate }
\end{aligned}
$$

As shown in the edge views of Figure 5(a), edge delaminations typically form at interfaces between $90^{\circ}$ plies and adjacent angle plies, shifting from one interface to its symmetric counterpart along the gage length. Previous work $[1,5]$ has indicated that measured stiffness loss agreed well with $E^{\star}$ calculations from equation (12) when delaminations were modeled at both interfaces between angle plies and $90^{\circ}$ plies and the sublaminated stiffnesses, $E_{i}$, were calculated from laminated plate theory. For the $\left[ \pm 25 / 90_{n}\right]_{s}$ family of layups, with delaminations modeled in the $-25 / 90$ interfaces,

$$
E^{\star}=\frac{4 E_{( \pm 25)_{S}+2 n E_{90}}}{(4+2 n)}
$$

which, for the $n=2$ laminate used to measure $G_{C}$, becomes 


$$
E^{\star}=\frac{E_{( \pm 25)_{S}}+E_{90}}{2}
$$

Using lamina properties from [9] ${ }^{+}$

$$
\begin{array}{ll}
E_{11}=134 \mathrm{GPa} & (19.5 \mathrm{Msi}) \\
E_{22}=10.2 \mathrm{GPa} & (1.48 \mathrm{Msi}) \\
\mathrm{G}_{12}=5.52 \mathrm{GPa} & (0.8 \mathrm{Msi}) \\
\nu_{12}=0.30 &
\end{array}
$$

in equations (14) and (11) yielded $a$ $G_{c}$ of $0.216 \mathrm{~kJ} / \mathrm{m}^{2}\left(1.233 \mathrm{in}-1 \mathrm{~b} / \mathrm{in}^{2}\right)$. Then, equation (11) was solved for $\varepsilon$,

$$
\varepsilon_{C}=\sqrt{\frac{2 G_{C}}{t\left(E_{L A M}-E^{\star}\right)}}
$$

and this $G_{C}$ was used to predict $\varepsilon_{c}$ for edge delamination onset in the other $\left[ \pm 25 / 90_{n}\right] s$ laminates. As shown in Figure 6, good agreement was observed for $n=1$ and 3 where edge delamination was observed (Fig. 4), but the predicted $\varepsilon_{c}$ was much higher than measured onset strains for the $n>4$ laminates where delaminations formed at $90^{\circ}$ ply cracks.

A similar procedure was used to predict delamination onset from $90^{\circ}$ matrix ply cracks. Because no significant stiffness loss was observed before local delamination onset [2], Hooke's law $\sigma=\mathrm{E}_{\mathrm{LAM}} \varepsilon$ was substituted into equation (9), and equation (9) was solved for $\varepsilon_{C}$ yielding

$$
\varepsilon_{c}=\frac{1}{E_{L A M}{ }^{t}} \sqrt{\frac{2 m G}{\left(\frac{1}{E_{L D} t_{L D}}-\frac{1}{E_{L A M} t}\right)}}
$$

\footnotetext{
TThese lamina properties were chosen because they resulted in the best comparison of $\mathrm{E}_{\text {LAM }}$ values calculated from laminated plate theory and measured modulus reported in reference 2 .
} 
Then, the $G_{C}$ from the $n=2$ laminate was used in equation (16) to predict $\varepsilon_{c}$ for local delamination onset in the other $\left[ \pm 25 / 90_{n}\right]_{s}$ laminates. For these local delaminations growing from a single matrix crack through the thickness of the entire set of $n 90^{\circ}$ plies, $t_{L D}$ and $E_{L D}$ were simply the thickness and modulus, respectively, of the four remaining $\pm 25^{\circ}$ plies, and $m$ was equal to 2 (Fig. 2). As shown in Figure 6, the delamination onset strains agreed fairly well for the $n>4$ laminates, and captured the trend of decreasing $\varepsilon_{c}$ with increasing thickness of the cracked $90^{\circ}$ plies.

The results in Figure 6 indicate that a strain energy release rate analysis will account for delamination onset for both sources of delamination, as illustrated in Figure 6, and account for the observed thickness dependence. However, the simple equations for total energy release rate shown in Figure 6 may not be sufficient for correlating all possible combinations of layups and delamination locations. previous work $[4,10,11]$ has indicated that for brittle resin composites with relatively low values of $G_{C^{\prime}}$ similar to values measured in this study for $T 300 / 934$, the mode I component of $G$, due to interlaminar tension only, controls the onset of delamination. This mode I dependence may explain why the transition from edge delamination to matrix ply crack induced delamination, that could be inferred from the predictions in Figure 6 to occur at $n=2$, does not occur until $n=4$. To verify the fracture mode dependence, the boundary value problem for local delamination must be formulated and solved to determine the contributions of interlaminar tension and shear to the total $G$ calculated in equations (10) and (11).

\section{TENSILE STIFFNESS AND STRENGTH}

As shown previously (Fig. 3), local delaminations that grew from matrix ply cracks in $[ \pm 25 / 90 n]_{s}$ laminates $(n>4)$ formed at lower strains than edge delaminations $(n<3)$. Figure 3 also shows that the laminate failure strains 
for $\left[ \pm 25 / 90_{n}\right]_{s}$ laminates that experienced edge delamination $(n<3)$ are nearly identical to the failure strains of $[ \pm 25]_{2 s}$ laminates $(n=0)$. But the laminates that experience local, matrix-ply crack induced delamination $(n>4)$ failed at lower strain levels. The nominal ultimate failure strain, $\varepsilon_{n u^{\prime}}$ decreased as $n$ increased. Furthermore, these $n>4$ laminates failed soon after the onset of local delamination. This data indicates that local delaminations from $90^{\circ}$ ply cracks create local strain concentrations in the primary load bearing $\pm 25^{\circ}$ plies that precipitates early laminate failures. Therefore, an analysis was developed to determine local strain concentrations in the load bearing plies in the vicinity of local delaminations.

\section{Local Strain Concentration Analysis}

Figure 7 shows through-thickness free-body diagrams for $\left[ \pm 25 / 90_{n}\right]_{s}$ laminates where (a) edge delamination has been modeled in the $-25 / 90$ interfaces, (b) where local delamination has been modeled in the $-25 / 90$ interfaces growing from a $90_{\mathrm{n}}^{\circ}$ matrix ply crack, and (c) where both edge and local delamination are modeled. Assuming the load at the top (T) and bottom (B) cross section (as shown in Fig. 7) must be equal, then substituting Hooke's law, yields an expression for the local strain concentration, $K$, from the top to the bottom through-thickness cross section,

$$
K=\frac{\varepsilon_{B}}{\varepsilon_{T}}=\frac{E_{T} t_{T}}{E_{B} t_{B}}
$$

For case (a) where only edge delamination occurs, the modulus of the top and bottom sections are identical, and are equal to $E^{*}$ as calculated by equation (13). Similarly, because all the plies continue to carry load, the thickness of the top and bottom cross sections are identical. Hence, edge delamination does not result in local strain concentrations in the individual plies. This conclusion is consistant with the observation that the $n<3$ 
laminates that edge-deldminate had the same failure strains as $[ \pm 25]$ s laminates. However, for case (b) where delaminations extend from a $90_{\mathrm{n}}^{\circ}$ ply crack, local strain concentrations do occur. The modulus and thickness of the top cross section are those of the original laminate. The modulus of the bottom cross section is simply the modulus of a $[ \pm 25]_{s}$ laminate. The thickness of the bottom cross section is simply the thickness of the four $\pm 25^{\circ}$ plies, because the isolated (cracked and delaminated) $90^{\circ}$ plies no longer carry load. Hence, the isolated $90^{\circ}$ plies are modeled as if they have been removed from the laminate (Fig. 5(b)). Table 1 shows the resulting local strain concentrations, $K$, in the load bearing \pm 25 plies calculated for the $\mathrm{n}=4,6,8$ laminates. These local strain concentrations should account for the reduction in $\left[ \pm 25 / 90_{n}\right]_{s}$ laminate nominal failure strains observed as $n$ increases from $n<3$, where only edge delamination is observed, to $n>4$, where local delamination is observed. However, as shown in Figure 4, the $n>4$ laminates exhibit a combination of edge and local delamination before final fracture, even though the local delamination occurs first. Hence, the free body in Figure 7 (c) may be more appropriate for evaluating local strain concentrations. For this case (c), the modulus of the top cross section is equal to $E^{\star}$ from equation (13) and the thickness is the original laminate thickness. The modulus and thickness of the bottom cross section is simply the modulus and thickness of a $[ \pm 25]_{s}$ laminate. The resulting local strain concentrations for this case (c) are also shown in table 1.

These local strain concentrations were used to predict the failure strain of the $n=4,6,8$ laminates. Because the $n<3$ laminates contained only edge delamination at failure, which does not result in local strain concentrations, their laminate nominal failure strains were also the in-situ failure strain, $\varepsilon_{F^{\prime}}$ of the $\pm 25^{\circ}$ plies. Hence, a mean laminate failure strain of 
0.0065 was assumed to be the failure strain of the primary load bearing $\pm 25^{\circ}$ plies (Fig. 3). Then, the $n=4,6,8$ laminate failure strains were predicted as $\varepsilon_{n u}=\varepsilon_{F} / K$, where $K$ was the local strain concentrations listed in table $1(c)$. The measured and predicted failure strains agreed well (Fig. 8). The trend of decreasing nominal failure strain with increasing thickness of the cracked ply is evident.

\section{$\underline{\text { Stiffness Loss }}$}

Because local delaminations growing from matrix ply cracks immediately result in local strain concentrations when they form, laminate failure may occur soon after the formation of local delaminations. This was indeed the case for $n>4$ laminates, as shown in Figure 3. Laminate failure occurred at, or just above, the onset strains for local delamination. If, however, these local delaminations were able to grow over a significant portion of the gage length, an associated stiffness loss would be observed. Substituting $a=\ell$ into equation (7) yields

$$
E=E_{L D}\left(\frac{t_{L D}}{t}\right)
$$

which represents the laminate modulus if the delaminations that formed at a matrix ply crack grew over the entire gage length. This totally delaminated modulus, $E_{L D^{\prime}}^{*}$ is not the same as $E^{*}$ calculated for edge delamination from equation (13), because the $90^{\circ}$ plies become isolated (cracked and delaminated on both sides as shown in Fig. 5(b)) for delaminations growing from matrix ply cracks. For example, Figure 9 shows the modulus (normalized by $E_{L A M}$ ) of $\left[ \pm 25 / 90_{n}\right]_{s}$ laminates $(n=1 / 2$ to 8$)$ completed delaminated at the $-25 / 90$ interfaces. For edge delamination, the largest modulus decrease is 23 percent, and occurs at $n=2$. However, if the delaminations grew from a $90_{\mathrm{n}}^{\circ}$ matrix ply crack, resulting in isolation of the $90_{\mathrm{n}}^{\circ}$ plies, then the laminate modulus 
decreases monotonically with increasing $n$. For $n=8$, a 49 percent decrease in laminate modulus would occur.

Comparison of Edge and Local Delamination

Figures 10 and 11 summarize the differences between edge delamination and matrix crack tip delamination. As shown in Figure 10, edge delaminations form at a constant strain $\varepsilon$, governed by equation (11). As edge delaminations grow across the width, the load carried by the delaminated strips near the edges is reduced. Eventually, when delamination has grown through the width, the entire laminate carries a reduced load at the same strain, and has a modulus $E^{*}$ determined by equation (12). Hence, edge delamination is inherently a stable fracture process. In contrast, Figure 11 shows that local delaminations form at matrix crack tips at a constant load $P$, governed by equation (10). As local delaminations begin to grow from the matrix crack tip and isolate the cracked plies, the strain in the uncracked plies near the locally delaminated region increases, with local strain concentrations estimated by equation (17). These local strain concentrations may result in failure of the uncracked plies that carry the load before extensive delamination growth occurs. If these delaminations were able to grow over the entire gage length, the uncracked plies would have an increased uniform nominal strain, and the laminate would have a reduced modulus determined by equation (18). Hence, delamination growth from matrix ply cracking may be unstable, leading to immediate laminate failure as was observed for $\left[ \pm 25 / 90_{n}\right]_{s} n=4,6,8$ laminates; but, in other laminates, local delamination may result in some stable growth before failure, or before other interfaces delaminate, which may further increase local strains and cause failure. This latter behavior has been observed under cyclic tensile loading of quasi-isotropic laminates [12]. 
SUMMARY AND CONCLUSIONS

A simple equation for the strain energy release rate, $G$, associated with local delaminations growing from matrix ply cracks was developed. This equation was then used to predict the local delamination onset strains in $\left[ \pm 25 / 90_{n}\right]_{s}$ laminates where delaminations grew from matrix cracks in the $90^{\circ}$ plies. This analysis correctly predicted the trend of lower delamination onset strains with increasing thickness of the cracked ply.

A simple technique was developed for calculating local strain concentrations in the primary load bearing plies near localized delaminations. These strain concentrations were used to successfully predict $\left[ \pm 25 / 90_{\mathrm{n}}\right]_{\mathrm{s}}$ laminate failure strains.

Based on these observations, and previous work, the following conclusions have been reached:

(1) Strain energy release rate, G, is a reasonable generic parameter for characterizing the interlaminar fracture behavior of composites. This G parameter accounts for the observed thickness dependence for both edge delamination and local delamination onset, and allows correlation between these two types of delaminations.

(2) Edge delamination is a stable fracture process that may reduce laminate modulus, and hence influence tensile strength, but will not cause premature laminate failures.

(3) Local delaminations growing from matrix cracks, however, create local strain concentrations that may lead to nominal laminate failure strains below the in-situ failure strain of the primary load bearing plies. 
REFERENCES

[1] O'Brien, T. K., Characterization of Delamination Onset and Growth in a Composite Laminate, Damage in Composites, ASTM STP 775, American Society for Testing and Materials, June 1982, pp. 140-167. Also NASA TM-81940, 1981.

[2] Crossman, F. W. and Wang, A. S. D., The Dependence of Transverse Cracking and Delamination on Ply Thickness in Graphite/Epoxy Laminates, Damage in Composite Materials, ASTM STP 775, American Society for Testing and Materials, 1982, pp. 118-139.

[3] Crossman, F. W., Warren, W. T., Wang, A. S. D., and Law, G. E., Initiation and Growth of Transverse Cracks and Edge Delamination in Composite Laminates, J. of Composite Materials, Supplemental Volume (1980), pp. 88-106.

[4] O'Brien, T. K., "Mixed-Mode Strain Energy Release Rate Effects on Edge Delamination of Composites," NASA TM 84592, January 1983. (Presented at ASTM symposium on the Effect of Defects in Composites, San Francisco, December 1982).

[5] O'Brien, T. K., The Effect of Delamination on the Tensile strength of Unnotched, Quasi-Isotropic, Graphite/Epoxy Laminates, Proceedings of the SESA/JSME Joint Conference on Experimental Mechanics, Part I, Hawaii, May 1982, pp. 236-243.

[6] Talug, A. and Reifsnider, K. L., Analysis of Stress Fields in Composite Laminates with Interior Cracks, Fibre Science and Technology, Vol. 12, 1979, pp. 201-215.

[7] Reifsnider, K. L. and Talug, A., Analysis of Fatigue Damage in Composite Laminates, International Journal of Fatigue, Vol. 3, No. 1, January 1980, pp. 3-11 
[8] Irwin, G. R., "Fracture," Handbuch Der Physik, Vol. 6, 1958, p. 551.

[9] Rodini, B. T., Jr. and Eisenmann, J. R., An Analytical and Experimental Investigation of Edge Delamination in Composite Laminates, Fibrous Composites in Structural Design, Plenum, New York, 1980, pp. 441-457.

[10] O'Brien, T. K., Johnston, N. J., Morris, D. H., and Simonds, R. A., A Simple Test for the Interlaminar Fracture Toughness of Composites, SAMPE Journal, Vol. 18, No. 4, July/August 1982, pp. 8-15.

[11] O'Brien, T. K., Johnston, N. J., Morris, D. H. and Simonds, R. A., Determination of Interlaminar Fracture Toughness and Fracture Mode Dependence of Composites Using the Edge Delamination Test, Proceedings of the International Conference on Testing, Evaluation, and Quality Control of Composites, University of Surrey, Guildford, England, September 1983, pp. 223-232 .

[12] O'Brien, T. K., Tension Fatigue Behavior of Quasi-Isotropic Graphite/ Epoxy Laminates, Proceedings of the Third Ris $\varnothing$ International Symposium on Metallurgy and Materials Science: Fatigue and Creep of Composite Materials, Roskilde, Denmark, Sept. 6-10, 1982, pp. 259-264. 
TABLE 1: LOCAL STRAIN CONCENTRATIONS IN $\pm 25^{\circ}$ PLIES OF $\left[ \pm 25 / 90_{n}\right]_{s}$ LAMINATES

$$
K=E_{T} t_{T} / E_{B} t_{B}
$$

\begin{tabular}{|cccc|}
\hline$n$ & (a) Edge Delam Only & (b) Local Delam Only & (c) Combined \\
\hline 4 & 1.00 & 1.66 & 1.29 \\
6 & 1.00 & 1.81 & 1.43 \\
8 & 1.00 & 1.95 & 1.57 \\
\hline
\end{tabular}




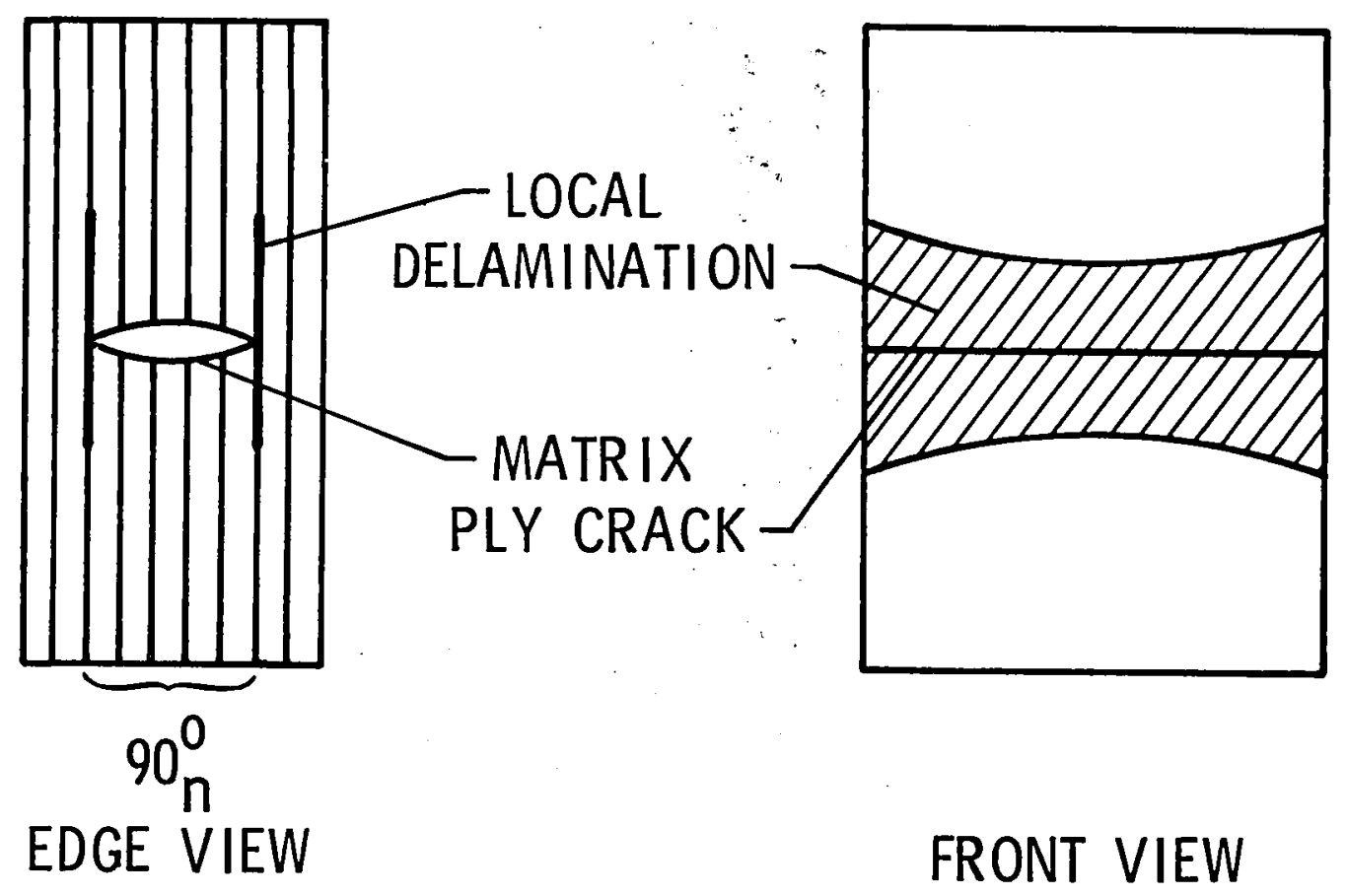

Fig. 1--Schematic of local delaminations growing from matrix cracks. 


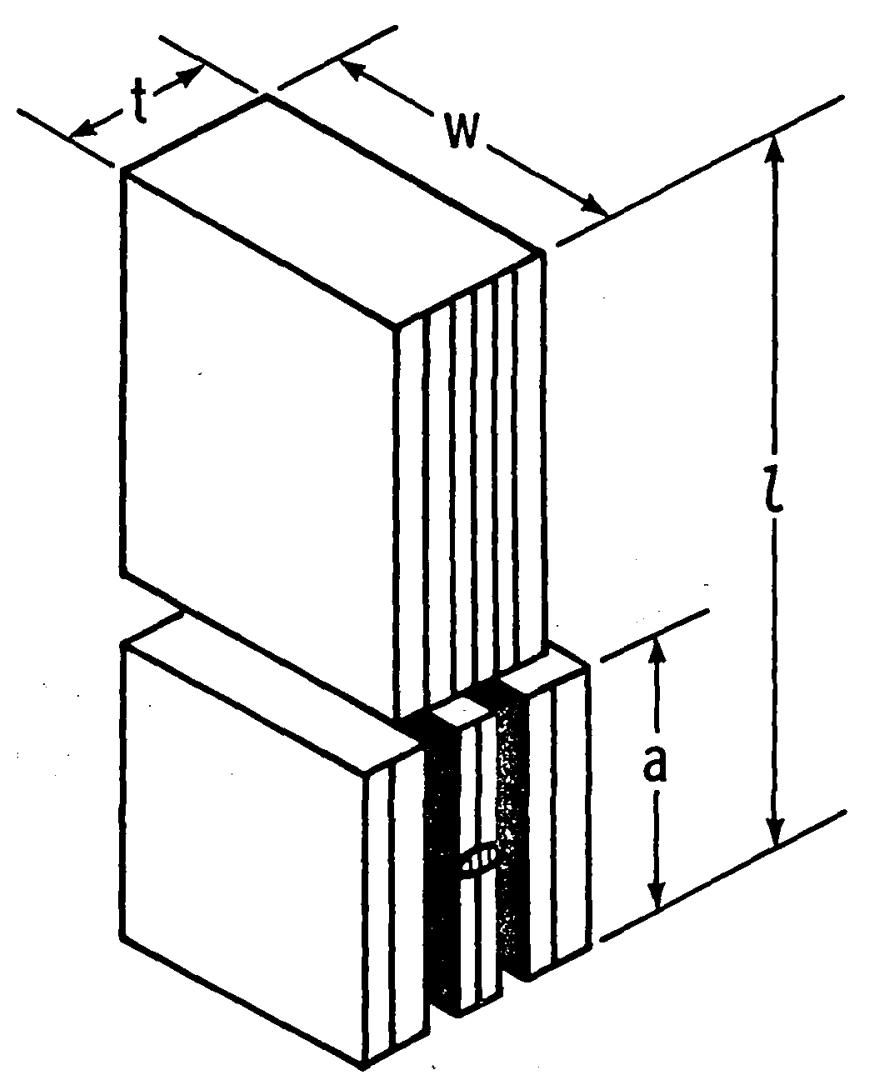

Fig. 2--Model of local delamination. 


$$
[ \pm 25 / 90]_{S} T 300 / 934
$$

o

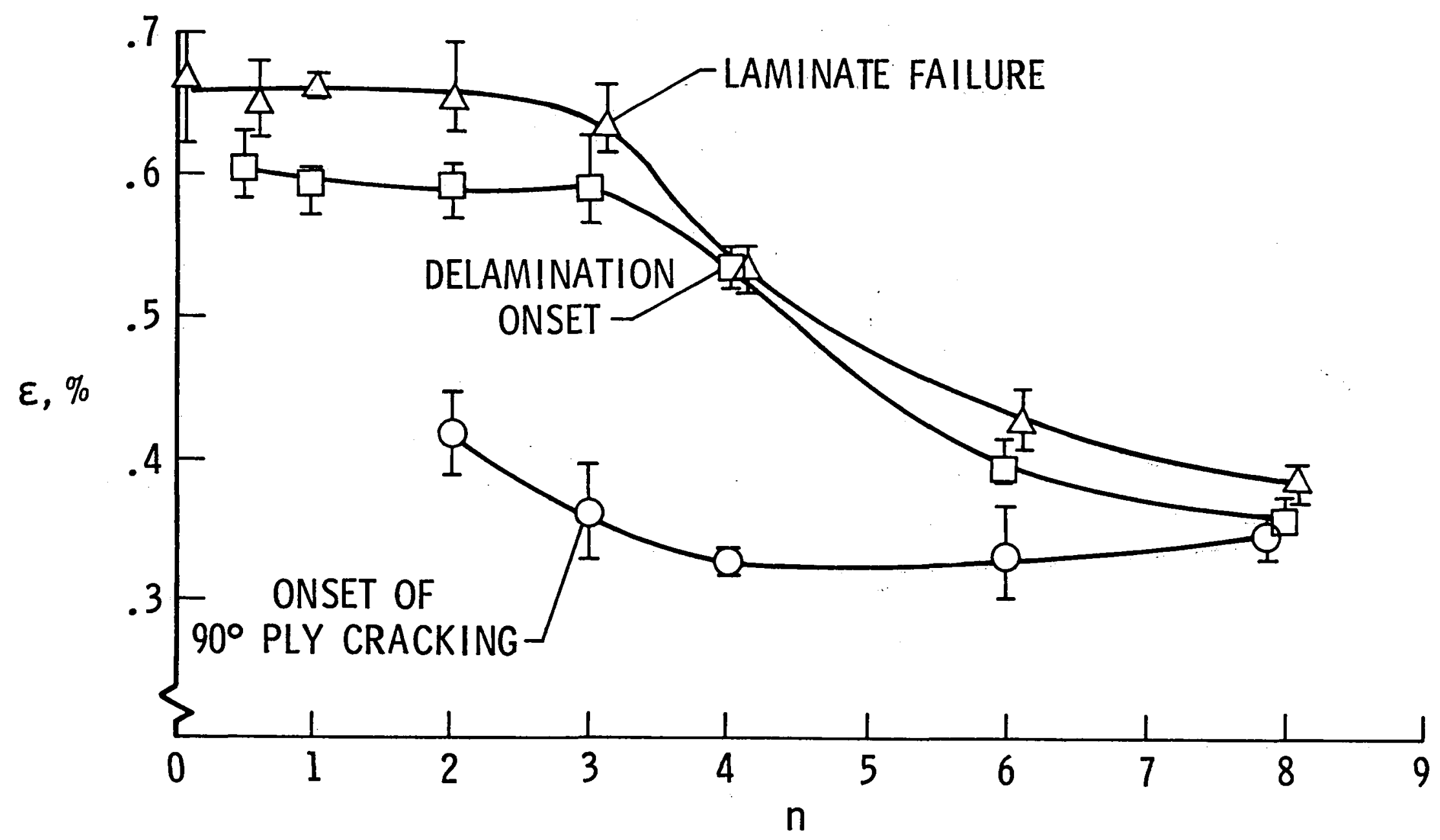

Fig. 3--Strain at onset of $90^{\circ} \mathrm{ply}$ cracking, delamination, and laminate failure. 


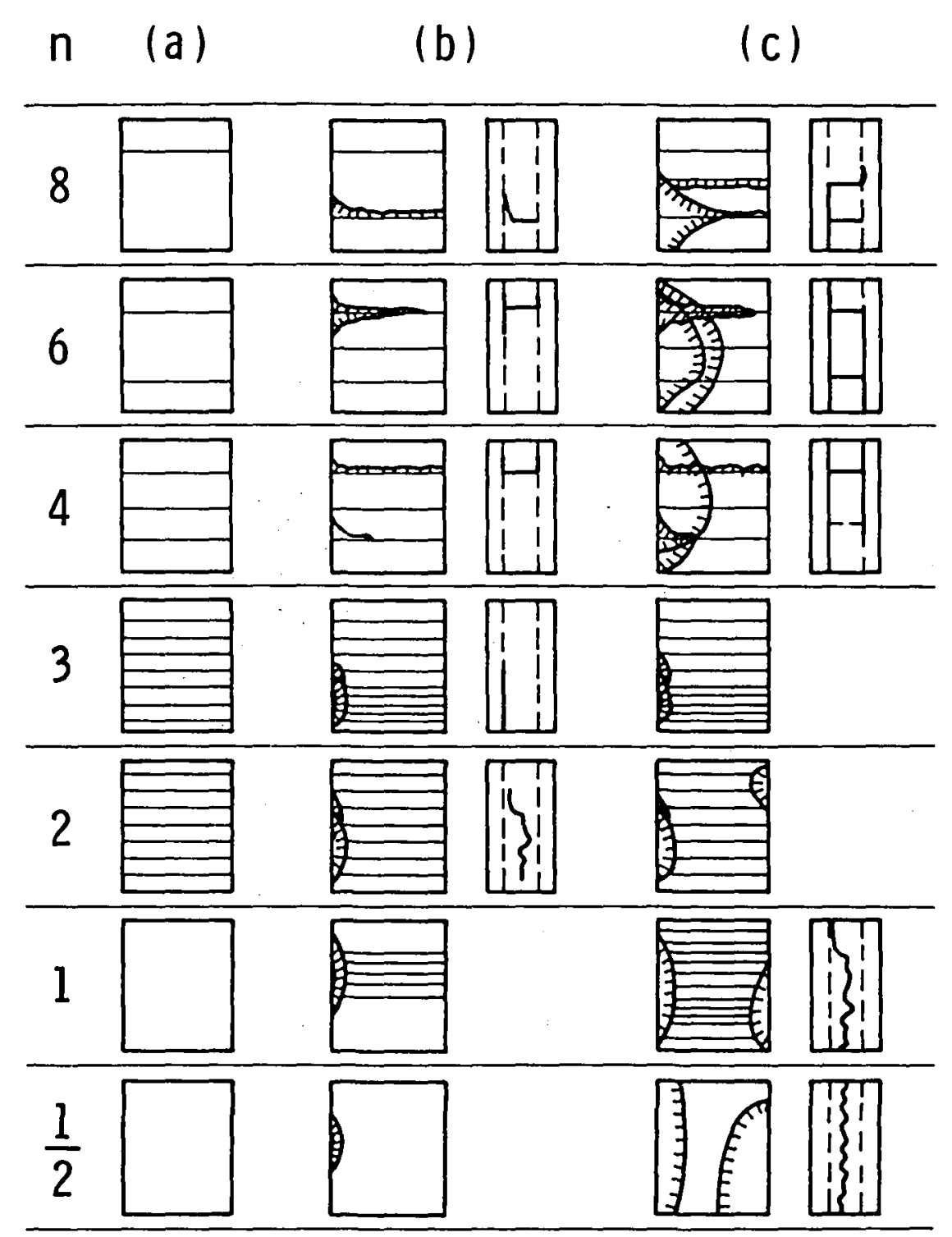

Fig. 4--Schematic of fracture sequences in $\left[ \pm 25 / 90_{n}\right]_{s}$ laminates. 


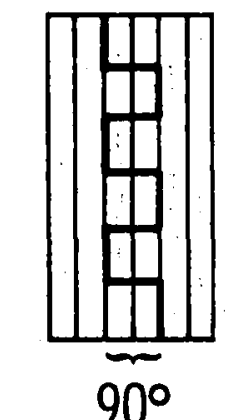

EDGE VIEW FRONT VIEW

(b)

LOCAL. DELAMINATION FROM MATRIX CRACKS

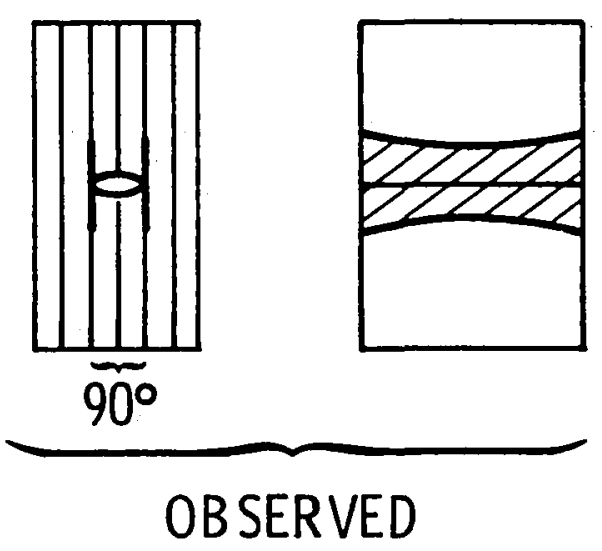

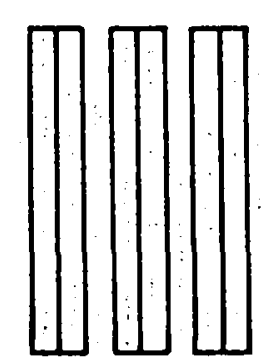

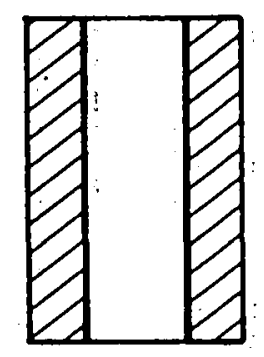

EDGE VIEW FRONT VIEW

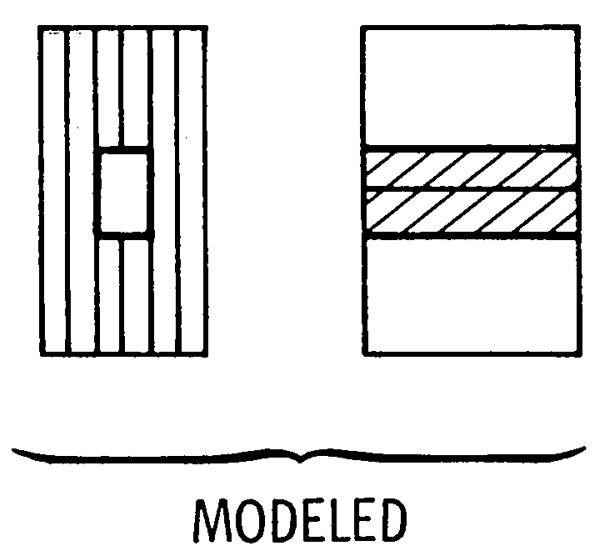

Fig. 5--Sources of delamination in unnotched laminates. 


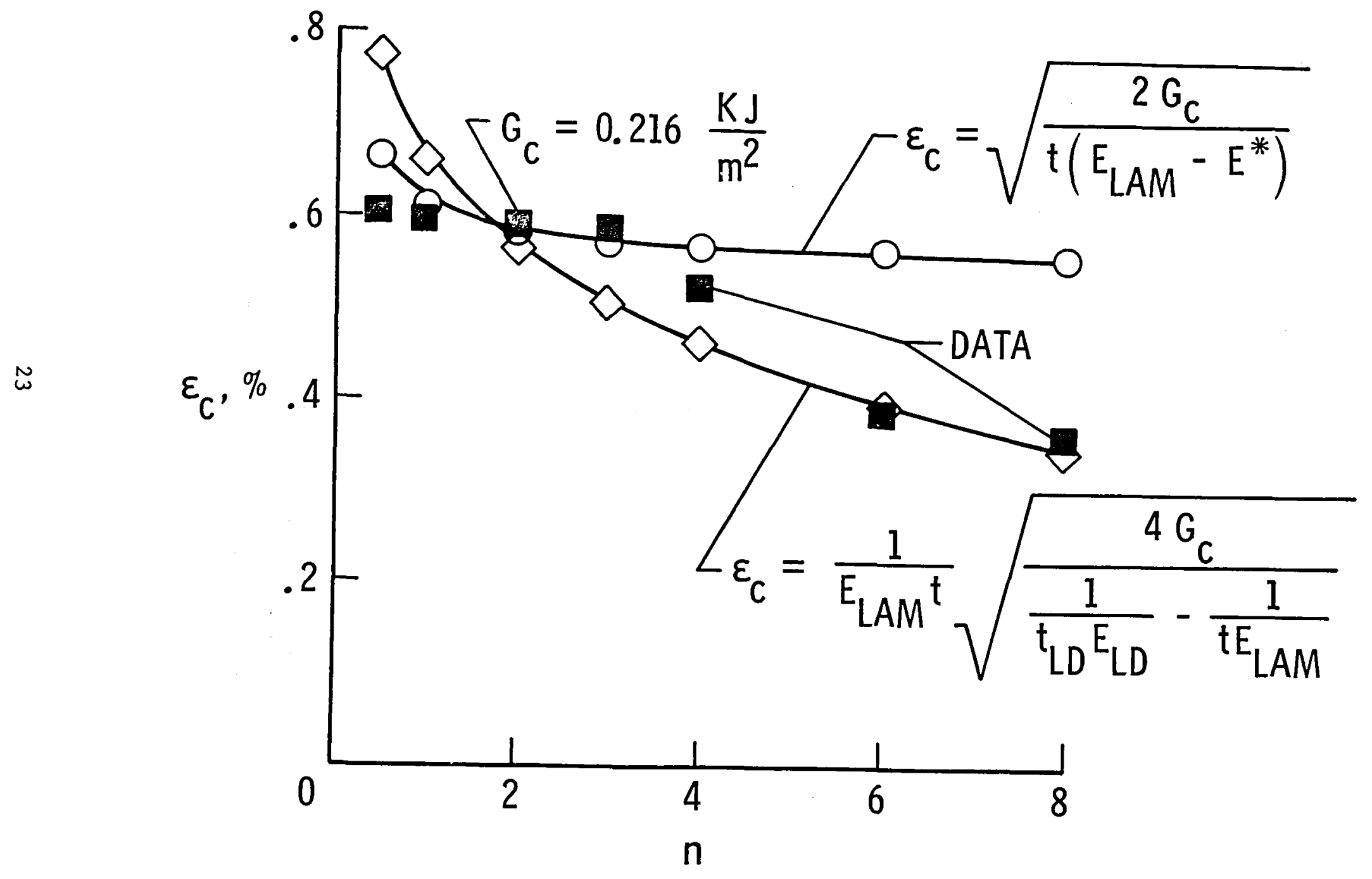

Fig. 6--Delamination onset in $\left[ \pm 25 / 90_{n}\right]_{s}$ laminates. 


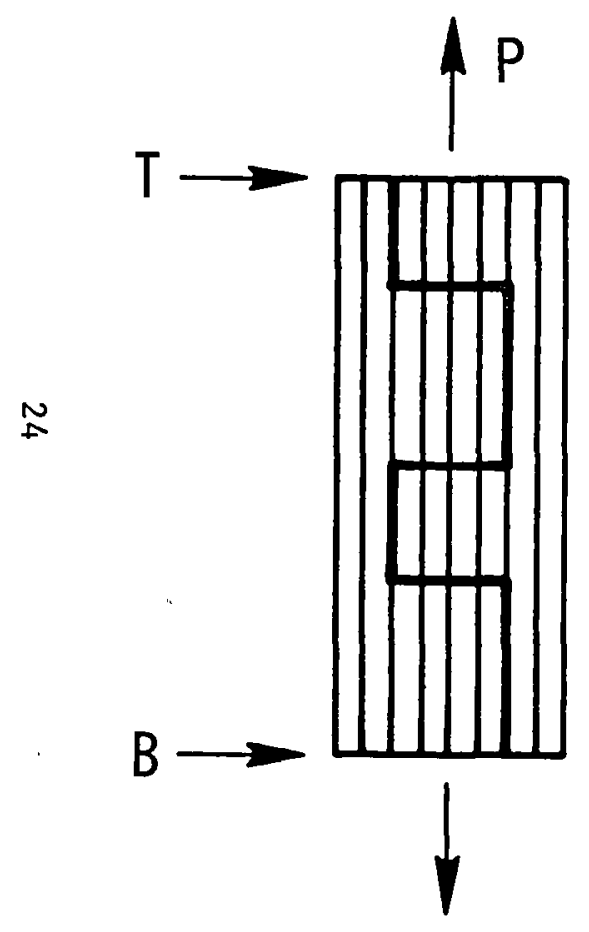

(a) EDGE

DELAMINATION

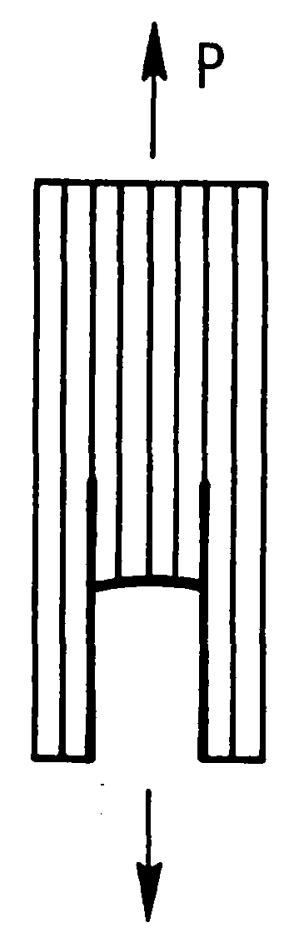

(b) LOCAL DELAMINATION

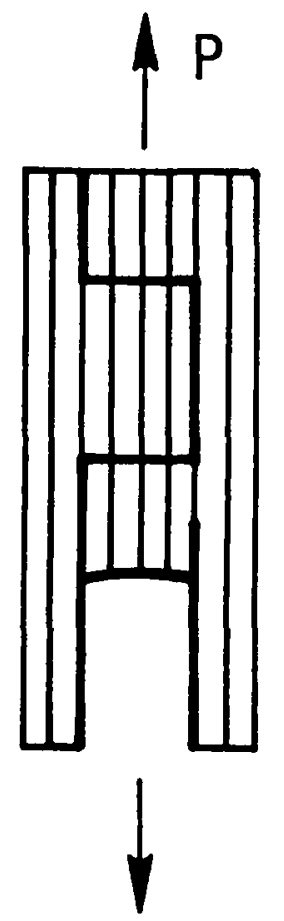

\section{LOCAL STRAIN} CONCENTRATION

$$
K=\frac{E_{T} t_{T}}{E_{B} t_{B}}
$$
Fig. 7-Free body diagrams of local through thickness sections of $\left[ \pm 25 / 90_{\mathrm{n}}\right]_{\mathrm{s}}$ laminates
containing delamination.

EDGE PLUS

LOCAL

\section{DELAMINATION}




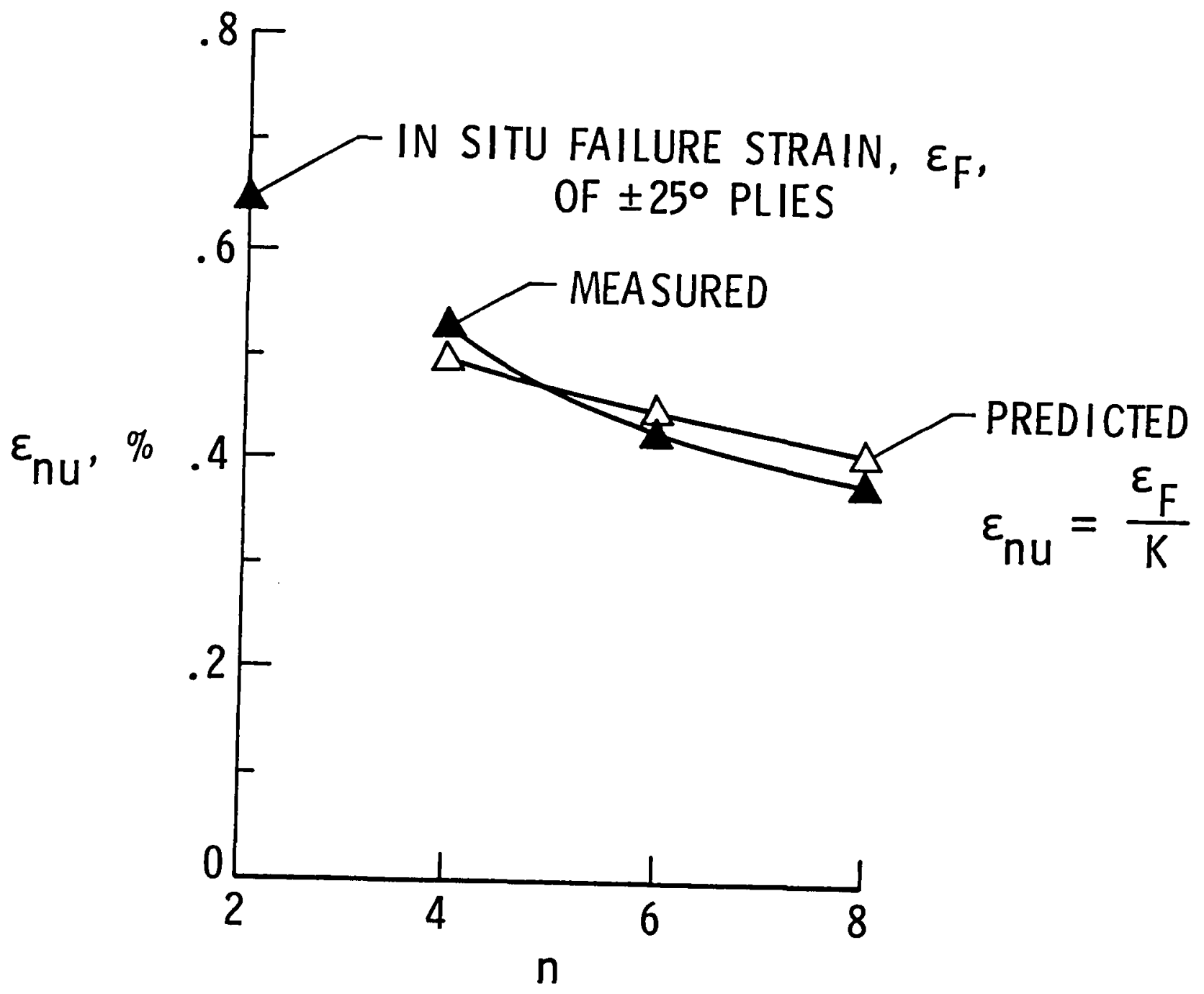

Fig. 8--Prediction of $\left[ \pm 25 / 90_{n}\right]_{s}$ laminate failure strains. 


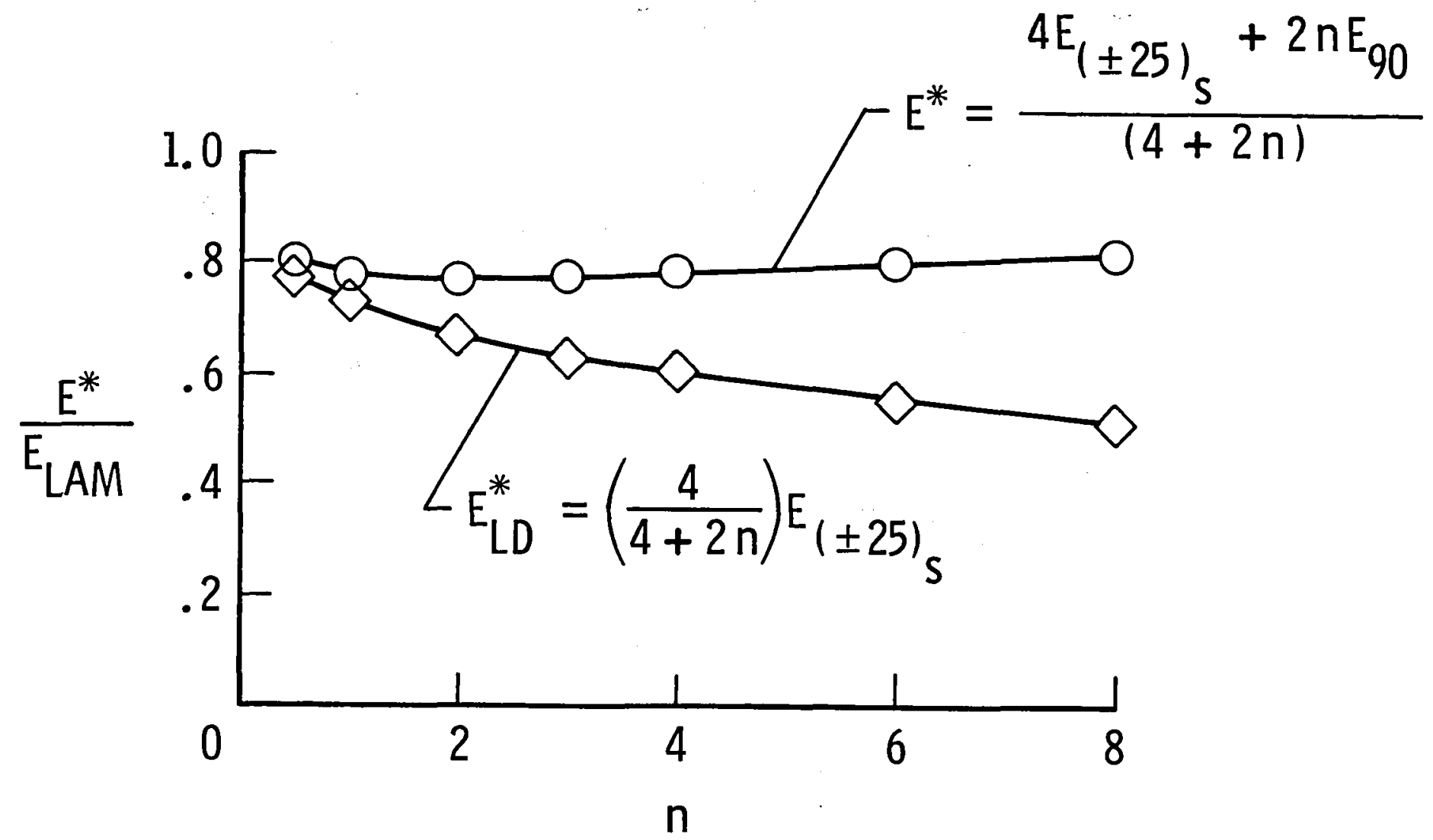

Fig. 9--Stiffness loss in $\left[ \pm 25 / 90_{n}\right]_{s}$ laminates, delaminated at $-25 / 90$ interfaces, with and without $90^{\circ}$ ply isolation. 


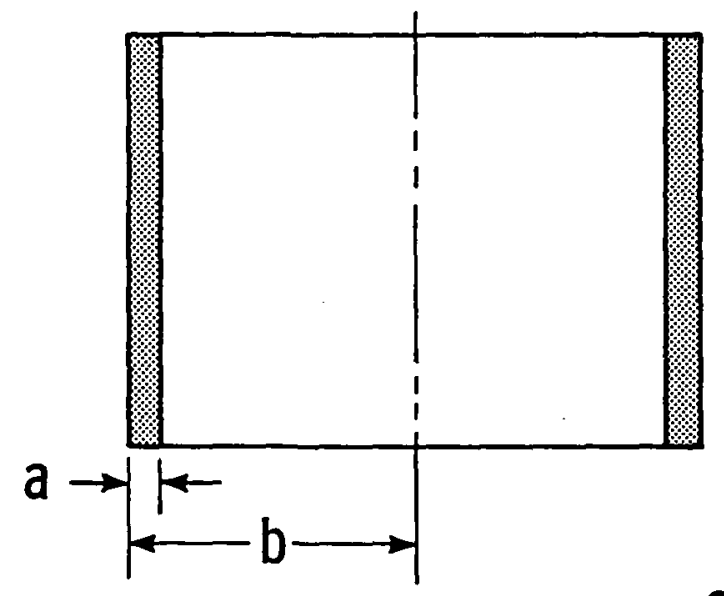

$$
G=\frac{\varepsilon^{2} t}{2}\left(E_{L A M}-E^{*}\right)
$$

$\varepsilon$
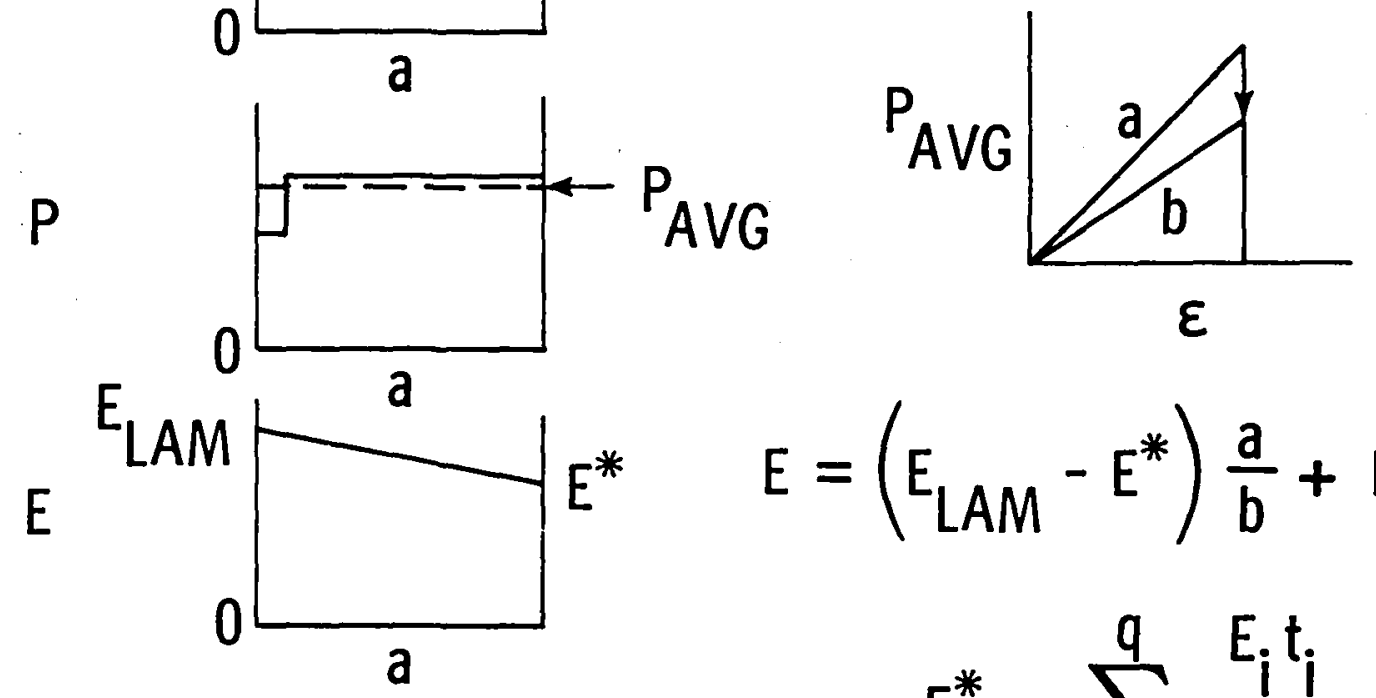

$$
\begin{gathered}
E=\left(E_{L A M}-E^{*}\right) \frac{a}{b}+E_{L A M} \\
E^{*}=\sum_{i=1}^{q} \frac{E_{i} t_{i}}{t}
\end{gathered}
$$

Fig. 10--Edge delamination behavior. 

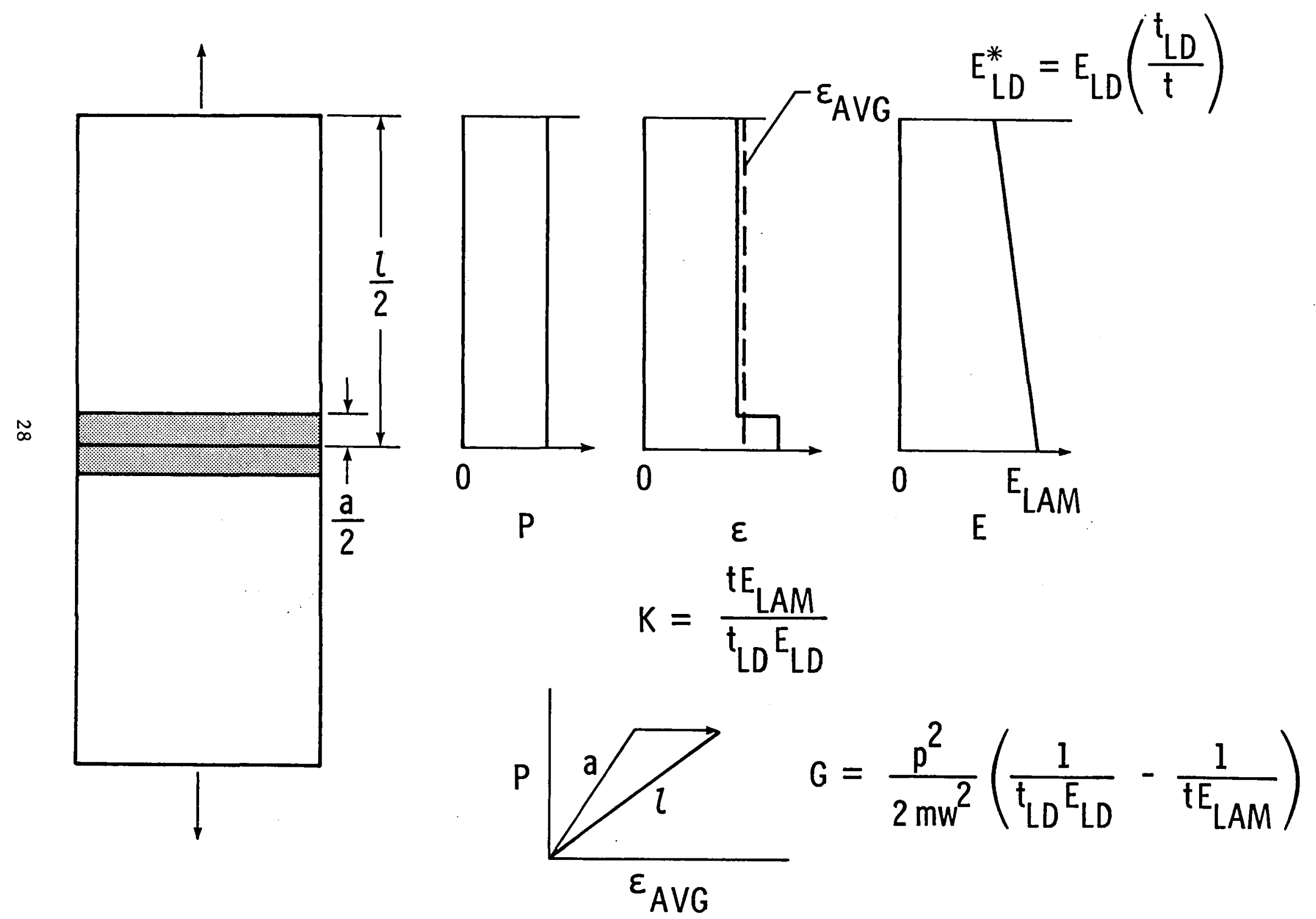

Fig. 11--Delamination from matrix ply cracks. 


\begin{tabular}{|c|c|}
\hline $\begin{array}{l}\text { 1. Report No. } \\
\text { NASA TM-85728, } \\
\text { USAAVSCOM } \\
\text { TR-83-B-6 }\end{array}$ & 3. Recipient's Catalog No. \\
\hline \multirow{2}{*}{$\begin{array}{l}\text { 4. Title and Subtitle } \\
\text { ANALYSIS OF LOCAL. DELAMINATIONS AND THEIR INFLUENCE } \\
\text { ON COMPOSITE LAMINATE BEHAVIOR }\end{array}$} & $\begin{array}{l}\text { 5. Report Date } \\
\text { January } 1984\end{array}$ \\
\hline & $\begin{array}{l}\text { 6. Performing Organization Code } \\
506-53-23-05\end{array}$ \\
\hline $\begin{array}{l}\text { 7. Author(s) } \\
\text { T. Kevin O'Brien }\end{array}$ & 8. Performing Organization Report No. \\
\hline \multirow{2}{*}{$\begin{array}{l}\text { 9. Performing Organization Name and Address } \\
\text { Structures Laboratory } \\
\text { USAAVSCOM Research and Technology Laboratories } \\
\text { NASA Langley Research Center } \\
\text { Hampton, VA } 23665\end{array}$} & 10. Work Unit No. \\
\hline & 11. Contract or Grant No. \\
\hline \multirow{2}{*}{$\begin{array}{l}\text { 12. Sponsoring Agency Name and Address } \\
\text { National Aeronautics and Space Administration } \\
\text { Washington, DC } 20546 \\
\text { U.S. Army Aviation and Systems Command } \\
\text { St. Louis, MO } 63166\end{array}$} & $\begin{array}{l}\text { 13. Type of Report and Period Covered } \\
\text { Technica } 1 \text { Memorandum }\end{array}$ \\
\hline & $\begin{array}{l}\text { 14. Army Project No. } \\
\text { IL161102AH45 }\end{array}$ \\
\hline
\end{tabular}

Presented at the ASTM Symposium on Delamination and Debonding of Materials, Pittsburgh, Pennsylvania, November 8-10, 1983.

16. Abstract

An equation was derived for the strain energy release rate, $G$, associated with local delamination growth from a matrix ply crack. The critical $\mathfrak{F}_{c}$ for edge delamination onset in $\left[ \pm 25 / 90_{2}\right]_{S}$ graphite epoxy laminates was measured and used in this equation to predict local delamination onset strains in $[ \pm 25 / 90 \mathrm{n}]_{\mathrm{s}}$, $n=4,6,8$ laminates. A simple technique for predicting strain concentrations in the primary load bearing plies near local delaminations was developed. These strain concentrations were responsible for reduced laminate nominal failure strains in laminates containing local delaminations. The influence of edge delamination and matrix crack tip delamination on laminate stiffness and strength was compared.

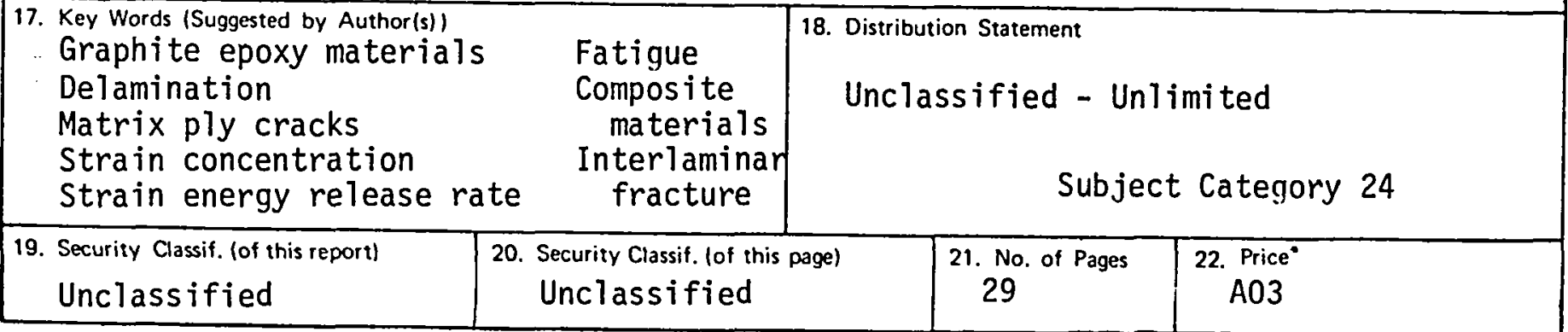


3 
$\checkmark$

!

I

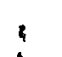

i 